\title{
HOW TO INVEST IN BELGIAN SHARES BY MULTIMOORA OPTIMIZATION
}

\author{
Willem K. M. Brauers ${ }^{1}$, Romualdas Ginevičius ${ }^{2}$ \\ ${ }^{1}$ Faculty of Business Management, Vilnius Gediminas Technical University, \\ Saulètekio al. 11, 10223 Vilnius, Lithuania \\ Faculty of Applied Economics, University of Antwerpen, F. Birontlaan 97, \\ B2600 Antwerpen, Belgium \\ ${ }^{2}$ Faculty of Business Management, Departmen of Economics and Management of Enterprises, \\ Vilnius Gediminas Technical University, Sauletekio al. 11, 10223 Vilnius, Lithuania \\ E-mails: ${ }^{1}$ willem.brauers@ua.ac.be (correspondingauthor); ${ }^{2}$ Romualdas.Ginevicius@vgtu.lt
}

Received 29 January 2013; accepted 12 August 2013

\begin{abstract}
Different multiple objectives expressed in different units make optimization difficult. Therefore, the internal mechanical solution of a Ratio System, producing dimensionless numbers, is preferred to weights, which are most of the time used to compare the different units. In addition, the ratio system creates the opportunity to use a second approach: a non-subjective Reference Point Theory. Therefore, the Reference Point Theory uses the ratios found in the ratio system as co-ordinates for the alternative solutions, which are then compared to a Maximal Objective Reference Point. The two approaches form a control on each other. This overall theory is called MOORA (Multi-Objective Optimization by Ratio Analysis). The results are still more convincing if a Full Multiplicative Form is added, three methods assembled under the name of MULTIMOORA. At that moment, the control by three different approaches forms a guaranty for a solution being as nonsubjective as possible. As to calculate the sum of three obtained ranks is not allowed, a theory of Ordinal Dominance is developed in order to remain in the ordinal sphere.

MULTIMOORA is used to decide upon an investment in Belgian shares on basis of a ranking in the BEL20 Index.
\end{abstract}

Keywords: Ratio System, Reference Point Theory, MOORA, Full Multiplicative Form, MULTIMOORA, Ordinal Dominance, BEL20 Index.

Reference to this paper should be made as follows: Brauers, W. K. M.; Ginevičius, R. 2013. How to invest in Belgian shares by MULTIMOORA optimization, Journal of Business Economics and Management 14(5): 940-956.

JEL Classification: G14, G2, M2.

\section{Introduction}

Shareholders participate in the capital of a company. In a company quoted on a Stock Exchange, this ownership is rather passive by excluding the shareholders, with exception for the reference shareholders, from any form of management. The shareholders have only voting rights in a yearly or in an extraordinary general assembly of these 
shareholders. In this way, their investment looks as speculative. This risky situation can even play for shareholders dispersed all over the world with the main Stock Exchanges not only in London and New York but also in Hong Kong, Singapore and Tokyo.

Investments in stocks from a selection of companies with a different activity or a different location will diminish the risk after the saying: "you must not put all your eggs in one basket". In addition, the advices of experts will help too. These advices may have different forms, coming from:

- The Credit Rating Agencies like Moody, Standard\&Poor's and Fitch. In 1909, John Moody published his first bond ratings on railroad bonds. If the agencies rate bonds of companies, this rating can also help for rating the economic safety of these companies. It is not very clear which methods the agencies use and there was also a growing criticism on their recent errors (White 2010).

- A general theory about investment in stocks such as the Buffet philosophy from his publications and his yearly speech to his shareholders.

- The advice of one or different experts based on: their personal experience, company balance analyses, interviews with managers or sampling concerning for instance:

a) one or different shares quoted at the moment,

b) share selections for the coming year,

c) a geographic choice like no European or American shares but shares from BRIC countries (Brazil, Russia, India, China) or from raw material producing countries.

- After the author's opinion up until now no advices on share selection exists based on a ranking in leading World Indices such as: AEX Amsterdam, CAC40 Paris, DAX30 Frankfurt, Dow Jones-Industrial New York, FTSE100 London, or Nikkei225 Tokyo. The BEL20 Index assembles the most important Belgian shares on NYSE-EURONEXT. These 20 shares form rather a defensive investment. More speculative would be to take a selection of the Brussels Mid Cap shares.

The authors decided not to include bank shares, namely KBC and Dexia. Their book value was very uncertain not only given the still existing consequences of the Sub Prime Crisis but also given their very important investments in countries in financial difficulties like Ireland, Portugal and Greece. Also Ageas, though an insurance company, is excluded as Ageas is the heritor from Fortis, now Paribas BNP, for parts of a Bad Bank. In this way, the BEL 20-index is reduced to 17 shares. Moreover, GDF Suez, though a French share, is included as being the successor of Electrabel, dominating the electricity market in Belgium. In addition, Belgian Electrabel is one of the most important crown jewels of GDF Suez, if not the most important.

Of course, Belgian shares could also be subject for Credit Rating Agencies, for a general theory about investment in stocks or for all kind of expert's judgments as indicated above. Nevertheless, no study is known which compare together all main Belgian shares of the BEL 20 or of the Brussels Mid Cap.

\section{The objectives chosen for selection of shares}

Different multiple objectives expressed in different units characterize Multi-Objective Optimization (MOO), a method followed in this study. Therefore, MOO has not to be mixed up with Cost-Benefit Analysis where all objectives are translated in money terms. 
A matrix assembles the data with vertically different objectives to be optimized and horizontally the 17 shares. The objectives concern the activity of the Belgian Stock Exchange on the last full day of 2010, namely Thursday December 30, 2010.

The best share will be the outcome of the following objectives:

1. Minimization of the last notation in EURO. The 20 shares of the Bell20-index are the most important Belgian shares. Above a certain bottom price, the cheaper they are the more attractive they are.

2. Minimization of the percentage deviation of this notation during the whole year 2010. Too much deviation would falsify the previous figure.

3. Maximization of the average day volume of trading during the last week divided by the average day volume of last year. A figure larger than one indicates more trading than normal.

4. Minimization of the notation divided by the earnings before interests, taxes, depreciation and amortization (EBITDA or Cash Flows).

5. Minimization of the notation to profit.

6. Maximization of the dividend to the notation.

7. Minimization of the notation to the book value.

8. Minimization of the PEG-ratio being the last notation of the share to profit divided by the profit growth being the cumulated profit growth between 2008 and 2009 translated on a yearly basis. A figure smaller than one indicates a relative cheap share.

9. Importance has still to be given to the different objectives. Until now all objectives were based on an equal importance. The introduction of the opinions of the analysts under the form of ratios will give more importance or not to some objectives on basis of their individual preferences. Minimization of the opinion ratio of the analysts is therefore the ninth objective. The analysts gave their opinion over the last 75 days. The opinions of the analysts lead to the following advices:

$-1-1.49$ buy

$-1.5-2.49$ increase your stock

$-2.5-3.49$ hold

$-3.5-4.49$ decrease your stock

$-4.5-5$ sell.

Information from financial newspapers will assist to fill in a table of data. This table is composed of 17 shares with 9 objectives or a total of 153 elements. At that moment, a method for optimization has to be chosen.

\section{The data assembled in a matrix}

A table (a matrix) assembles the data with vertically numerous objectives, criteria (a weaker form of objectives) or indicators and horizontally alternative solutions, represented in this application by different companies (Table 1 ). 
Table 1. Matrix of Responses

\begin{tabular}{|c|c|c|c|c|c|c|}
\hline & obj.1 & obj.2 & $\ldots$ & obj.i & $\ldots \ldots$ & obj.n \\
\hline Alternative solution 1 & $X$ & $\mathrm{X}$ & $\mathrm{X}$ & $\mathrm{X}$ & $X$ & $X$ \\
\hline Alternative solution 2 & $X$ & $\mathrm{X}$ & $X$ & $X$ & $X$ & $X$ \\
\hline n........... & $X$ & $X$ & $X$ & $\mathrm{X}$ & $X$ & $X$ \\
\hline Alternative solution $\mathrm{j}$ & $X$ & $\mathrm{X}$ & $X$ & $X$ & $X$ & $\mathrm{X}$ \\
\hline n.w. & $X$ & $\mathrm{X}$ & $\mathrm{X}$ & $\mathrm{X}$ & $X$ & $X$ \\
\hline Alternative solution $\mathrm{m}$ & $X$ & $\mathrm{X}$ & $X$ & $X$ & $\mathrm{X}$ & $X$ \\
\hline
\end{tabular}

Once agreement reached about alternatives and objectives, a decision has to be taken how to read the Response Matrix, either horizontally or vertically.

The Additive Weighting Procedure (MacCrimmon 1968: 29-33), which was called SAW, Simple Additive Weighting Method, by Hwang and Yoon (1981: 99) and Usual Reference Point Methods read the response matrix in a horizontal way. As the weights add to one, a new super-objective is created and consequently it is difficult to speak of multiple objectives. Usual Reference Point Theory is non-linear, whereas non-additive scores replace the weights. The non-additive scores take care of normalization, but being non-additive the comments on the weights adding to one and consequently creating a super-objective is absent here.

With weights and scores normalization of different units is mixed with the importance of objectives. Consequently, the proportion between normalization and importance is unknown. Nevertheless many methods for multi-objective optimization use weights like AHP (Saaty 1988) or methods of the French School (starting with ELECTRE, Roy et al. 1966).

Vertical reading of the Response Matrix means that normalization is not needed as each column is expressed in the same unit. TOPSIS (Hwang, Yoon 1981) and VIKOR (Opricovic, Tzeng 2004) read the Response Metric vertically, based on Euclidean or Rectangular Metrics ${ }^{1}$. In addition, Chakraborty (2011) checked the six famous methods of Multi-Objective Decision Making for decision making in manufacturing. Next Table 2 shows the results.

We have to mention that none of these methods was involved in a ranking of shares in one or another country as has been done here for the Belgian shares.

In Table 1 if each column is translated into ratios, dimensionless measures are created and the columns become comparable to each other. Different kinds of ratio are possible but Brauers and Zavadskas (2006) proved that the best one is based on the square root in the denominator. In conformity with this reasoning, the Ratio System, which forms the basis of the MOORA method, follows the vertical reading of the matrix. Figure 1 shows the exact relation between the two methods of MOORA and in addition to MULTIMOORA, MOORA plus the Full Multiplicative Form.

\footnotetext{
${ }^{1}$ Brauers (2008) maintains that Euclidean and Rectangular Metrics violate Consumer Surplus.
} 
Table 2. Comparative performance of some Multi-Objective Methods

\begin{tabular}{lccccc}
\hline MOO & $\begin{array}{c}\text { Computational } \\
\text { time }\end{array}$ & Simplicity & $\begin{array}{c}\text { Mathematical } \\
\text { calculations }\end{array}$ & Stability & $\begin{array}{c}\text { Information } \\
\text { type }\end{array}$ \\
\hline MOORA & Very less & Very simple & Minimum & Good & Quantitative \\
\hline AHP & Very high & Very critical & Maximum & Poor & Mixed \\
\hline TOPSIS & Moderate & $\begin{array}{c}\text { Moderately } \\
\text { critical }\end{array}$ & Moderate & Medium & Quantitative \\
\hline VIKOR & Less & Simple & Moderate & Medium & Quantitative \\
\hline ELECTRE & High & $\begin{array}{c}\text { Moderately } \\
\text { critical }\end{array}$ & Moderate & Medium & Mixed \\
\hline PROMETHEE (a) & High & $\begin{array}{c}\text { Moderately } \\
\text { critical }\end{array}$ & Moderate & Medium & Mixed \\
\hline
\end{tabular}

Note: (a) PROMETHEE since 1984-1986, Brans et al. (1984, 1986).

\section{Multi-Objective Optimization by Ratio Analysis (MOORA)}

\subsection{The two parts of MOORA}

The method starts with a matrix of responses of different alternatives on different objectives:

$$
\left(x_{i j}\right),
$$

with: $\boldsymbol{x}_{\boldsymbol{i} j}$ as the response of alternative $j$ on objective $i ; i=1,2, \ldots, n$ as the objectives; $j=1,2, \ldots, m$ as the alternatives.

MOORA goes for a ratio system in which each response of an alternative on an objective is compared to a denominator, which is representative for all alternatives concerning that objective. For this denominator the square root of the sum of squares of each alternative per objective is chosen. Brauers, Zavadskas (2006) proved that this is the most robust choice:

$$
x_{i j^{*}}=\frac{x_{i j}}{\sqrt{\sum_{j=1}^{m} x_{i j}^{2}}},
$$

with: $x_{i j}=$ response of alternative $j$ on objective $i ; j=1,2, \ldots, m$; $m$ the number of alternatives; $i=1,2, \ldots, n ; n$ the number of objectives; $x_{i j}{ }^{*}=$ a dimensionless number representing the response of alternative $j$ on objective $i$, meaning that the number is no more expressed in money, weights, length, volume etc.

Dimensionless Numbers, having no specific unit of measurement, are obtained for instance by deduction, multiplication or division. The normalized responses of the alternatives on the objectives belong to the interval $[0 ; 1]$. However, sometimes the interval could be $[-1 ; 1]$. Indeed, for instance in the case of productivity growth some sectors, regions or countries may show a decrease instead of an increase in productivity i.e. a negative dimensionless number. 


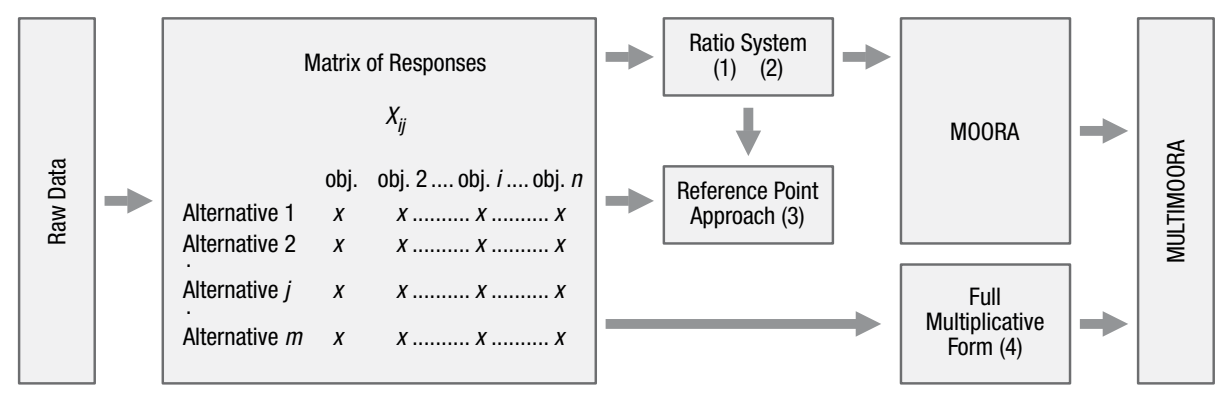

Fig. 1. Diagram of MULTIMOORA

Note: The figures between brackets refer to the formulas on next page

For optimization, these responses are added in case of maximization and subtracted in case of minimization:

$$
y_{j}{ }^{*}=\sum_{i=1}^{i=g} x_{i j}{ }^{*}-\sum_{i=g+1}^{i=n} x_{i j}{ }^{*},
$$

with: $i=1,2, \ldots, g$ as the objectives to be maximized; $i=g+1, g+2, \ldots, n$ as the objectives to be minimized; $y_{j}{ }^{*}=$ the total assessment of alternative $j$ with respect to all objectives.

An ordinal ranking in a descending order of the $y_{j}{ }^{*}$ shows the final preference.

For the second part of MOORA the Reference Point Theory is chosen with the MinMax Metric of Tchebycheff as given by the following formula (Karlin; Studden 1966: 280):

$$
\underset{(j)}{\operatorname{Min}}\left\{\max _{(i)}\left|r_{i}-x_{i j} *\right|\right\},
$$

with: $r_{i}$ as the reference point and $\left|r_{i}-x_{i j}{ }^{*}\right|$ the absolute value if $x_{i j}{ }^{*}$ is larger than $r_{i}$ for instance by minimization.

This reference point theory starts from the already normalized ratios as defined in the MOORA method, namely formula (1). A reference point possessing as co-ordinates the dominating co-ordinates per attribute of the candidate alternatives and which is designated as the Maximal Objective Reference Point is preferred. This approach is realistic and non-subjective as the co-ordinates, which are selected for the reference point, are realized in one of the candidate alternatives. The alternatives A $(10 ; 100), \mathrm{B}(100 ; 20)$ and C $(50 ; 50)$ will result in the Maximal Objective Reference Point $R_{m}(100 ; 100)$.

Given the composition of equation (3) the results are ranked in an ascending order.

\subsection{The importance given to an objective by the Attribution Method in MOORA}

It may look that one objective cannot be much more important than another one as all their ratios are smaller than one (see formula 1) Nevertheless it may turn out to be necessary to stress that some objectives are more important than others. In order to give more importance to an objective its ratios could be multiplied with a Significance Coefficient. 
In the Ratio System in order to give more importance to an objective, its response on an alternative under the form of a dimensionless number is multiplied with a Significance Coefficient:

$$
\ddot{y}_{j}{ }^{*}=\sum_{i=1}^{i=g} s_{i} x_{i j}{ }^{*}-\sum_{i=g+1}^{i=n} s_{i} x_{i j}{ }^{*},
$$

with: $i=1,2, \ldots, g$ as the objectives to be maximized; $i=g+1, g+2, \ldots, n$ as the objectives to be minimized; $s_{i}=$ the significance coefficient of objective $i ; \ddot{y}_{j}{ }^{*}=$ the total assessment with significance coefficients of alternative $j$ with respect to all objectives. In the Reference Point Approach, importance is a consequence of formula (2 bis) of the Ratio System.

\section{MULTIMOORA}

In his book of 2004, Brauers (2004c) described the three parts of MULTIMOORA: 1) the Ratio System Approach, producing dimensionless ratios, 2) the Reference Point Approach, but still based on scores, 3) the Full Multiplicative Form. Some time later (2004b and 2004a) he switched over to a Reference Point Approach which uses for coordinates of each alternative the ratios found in the ratio system. These coordinates are then compared to the coordinates of the Maximal Objective Reference Point (see therefore 4.1). In this way, dimensionless measures were obtained again. The synthesis of these two approaches was called later: MOORA (Brauers, Zavadskas 2006). In 2010, a third approach was added and MULTIMOORA was born (Brauers, Zavadskas 2010a). Indeed, MULTIMOORA is composed of MOORA and of the Full Multiplicative Form of Multiple Objectives. In this way as up till now no other approach is known satisfying all conditions of robustness towards multi-objective optimization and including three or more methods, MULTIMOORA becomes the most robust system of multiple objectives optimization (for the conditions of robustness in multi-objective optimization, see: Brauers, Zavadskas 2010b: 70-71, 2010c).

Point 4 above explained MOORA (Multi-Objective Optimization by Ratio Analysis). The Full Multiplicative Form of Multiple Objectives of MULTIMOORA remains to be explained.

\subsection{The Full Multiplicative Form of Multiple Objectives}

Mathematical economics is familiar with the multiplicative models like in production functions (e.g. Cobb-Douglas and Input-Output formulas) and demand functions (Teekens, Koerts 1972).

Allen (1957: 473) launched the "bilinear and quadratic form" as: $\sum_{r} \sum_{s} a_{r s} x_{r} y_{s}$, for us concerning weights and objectives but with interrelations only examined two by two.

For Keeney and Raiffa (1993: 234) besides additive utilities, a utility function may also include a multiplication of the attributes. The two dimensional $\mathrm{u}(\mathrm{y}, \mathrm{z})$ can then be expressed as a multilinear utility function. This representation mixes additive and multiplicative parts (Brauers 2004c: 228). 
For Keeney (1973: 110) the additive form is rather a limiting case of the multiplicative utility function, for us the SAW method as explained earlier in section 3 .

The danger exists that the multiplicative part becomes explosive. The multiplicative part of the equation would then dominate the additive part and finally would bias the results.

Considering these shortcomings, preference is given to a method that is non-linear, nonadditive, does not use weights and does not require normalization. Such multiplicative form for multi-objectives was introduced by Miller and Starr in 1964 (Miller, Starr 1969: 237-239) and further developed by Brauers (2004c: 227-245).

The following n-power form for multi-objectives is called from now on a Full-Multiplicative Form in order to distinguish it from the above-mentioned mixed forms:

$$
U_{j}=\sum_{i=1}^{n} x_{i j},
$$

with: $j=1,2, \ldots, m ; m$ the number of alternatives; $i=1,2, \ldots, n ; n$ being the number of objectives; $x_{i j}=$ response of alternative $j$ on objective $i ; U_{j}=$ overall utility of alternative $j$.

The overall utilities $\left(U_{j}\right)$, obtained by multiplication of different units of measurement, become dimensionless. The outcome of this presentation is nonlinear, which presents an advantage, as the utility function of human behavior toward several objectives has to be considered as nonlinear.

\subsection{The description of the importance of an objective in the Full Multiplicative Form}

Stressing the importance of an objective could be done by allocating a coefficient $\beta$ (a Significance Coefficient) on condition that this is done with unanimity or at least with a strong convergence in opinion of all the stakeholders concerned.

Formula (4) has then to run as follows:

$$
U_{j}=\sum_{i=1}^{n} \beta_{i} x_{i j},
$$

with: $j=1,2, \ldots, m ; m$ the number of alternatives; $i=1,2, \ldots, n ; n$ being the number of attributes or objectives; $x_{i j}=$ response of alternative $j$ on attribute $i$ of objective $i$; the $\beta$ are measures of importance (significance coefficients); $U j=$ overall utility of alternative $j$. $U j$ is a dimensionless indicator.

Several situations may occur, related to the $\beta$-coefficients. All $\beta$-coefficients are assumed larger than zero.

Supposing three attributes and two alternatives: $n=3, m=2$

a) in general:

$U_{1}=\beta_{1} \beta_{2} \beta_{3} x_{11} x_{21} x_{31}$;

$U_{2}=\beta_{1} \beta_{2} \beta_{3} x_{12} x_{22} x_{32}$.

b) the $\beta$-coefficients have the form of weights:

$0 \leq \beta_{1} \leq 1 ; 0 \leq \beta_{2} \leq 1 ; \beta_{3}=1-\beta_{1}-\beta_{2}$. 
with the following outcome:

$U_{1}=\beta_{1} \beta_{2}\left(1-\beta_{1}-\beta_{2}\right) x_{11} x_{21} x_{31}$;

$U_{2}=\beta_{1} \beta_{2}\left(1-\beta_{1}-\beta_{2}\right) x_{12} x_{22} x_{32}$.

c) the $\beta$-coefficients have the form of ratios:

$\beta_{1}=1 / \gamma_{1} ; \beta_{2}=1 / \gamma_{2} ; \beta_{3}=1 / \gamma_{3}$ (these ratios have the form of weights if they satisfy the same conditions as under $b$ ).

$U_{1}=\left(1 / \gamma 1 / \gamma_{2} 1 / \gamma_{3}\right) x_{11} x_{21} x_{31}$

$U_{2}=\left(1 / \gamma_{1} 1 / \gamma_{2} 1 / \gamma_{3}\right) x_{12} x_{22} x_{32}$.

\section{Conclusion}

In the three cases, the relation between the two overall utilities remains the same:

$$
\frac{U_{1}}{U_{2}}=\frac{x_{11} x_{21} x_{31}}{x_{12} x_{22} x_{32}} \text {. }
$$

The following conclusions arise from the invariance between the overall utilities.

Rule I

In the full-multiplicative form, the relation between the utilities does not change if more importance is given to an objective by multiplying it by a factor. Indeed, at that moment all alternatives are multiplied with that factor.

Consequence 1

In the full-multiplicative form, the introduction of weights is meaningless. Indeed weights are here in fact multiplying coefficients.

Rule II

Rule II implies that in the full-multiplicative form an attribute of an objective can be divided by a constant without changing the relation between the overall utilities of the alternatives.

Consequence 2

In the full-multiplicative form an attribute of the size $10,10^{2}, 10^{3}, 10^{6}, 10^{9}$ etc. can be replaced by the unit size without changing the relationship between the utilities of the alternatives.

This consequence is extremely important for attributes expressed in monetary units. Instead of expressing an attribute in tens, hundreds, thousands, millions, billions for instance of dollars, the use of one digit in the integer part is sufficient.

General Conclusion

Designating a Beta Coefficient as a significance coefficient is senseless. How we can give then importance to an objective?

Allocating an exponent to an attribute of an objective, used as a significance coefficient, signifies stressing the importance of this attribute (see Miller, Star 1969: 237-239). 


\subsection{Objectives moving in a different direction in the Full Multiplicative Form}

How is it possible to combine a minimization of objectives with the maximization of other objectives?

Mathematically, ratio analysis shows the harmony between addition and subtraction. Here the Full Multiplicative Form shows the harmony between multiplication and division.

Therefore, the objectives to be minimized are denominators in the formula:

$$
U_{j}^{\prime}=\frac{A_{j}}{B_{j}},
$$

with: $A_{j}=\prod_{i=1}^{g} x_{i j}, j=1,2, \ldots, m ; m$ the number of alternatives; $i=1,2, \ldots, n ; n$ the number of objectives; $g=$ the number of objectives to be maximized, with: $B_{j}=\prod_{i=g+1}^{n} x_{i j}, n-g=$ the number of objectives to be minimized $U_{j}^{\prime}:$ the utility of alternative $j$ with objectives to be maximized and objectives to be minimized.

It is true that the Full Multiplicative Form reads horizontally in the Response Matrix of Table 1. Nevertheless, with the full-multiplicative form, the overall utilities, obtained by multiplication of different units of measurement, become dimensionless measures. This situation would not bias the outcomes amidst the several alternatives as the last ones are represented by dimensionally homogeneous equations, being: "formally independent of the choice of units" (De Jong 1967: 28).

In the Full Multiplicative Form, a problem may arise for zero and negative values. In formulas 4 and 6 a zero for one alternative would make the outcome equal to zero. A negative number would make the outcome negative. Even worse, in formula 6 a zero in the denominator with a non-zero numerator will make the outcome non-defined, with once again a negative denominator making the outcome negative.

Therefore, the index number 100 replaces the zero number. At that moment for instance 96.6 substitutes the negative number of minus 3.4. Consequently, 103.4 represents the positive number of 3.4. Is this solution acceptable? The answer is yes if this change is logically applied for an entire column of table 1. At that moment, the results of the multiplication will change, anyway of no importance as these results are senseless as being dimensionless measurements. However, the overall ranking will become meaningful.

The fact that MULTIMOORA assembles all existing methods expressed in dimensionless measures for multi-objective optimization presents a unique feature for this multiobjective optimization.

\section{The Theory of Ordinal Dominance}

First, in the not too complicated cases, a summary of the ranking of the three MULTIMOORA methods was done on view. Later, for very large matrices a Theory of Ordinal Dominance was developed (Brauers, Zavadskas 2011a; Brauers et al. 2011). 


\subsection{Axioms on Ordinal and Cardinal Scales}

1. A deduction of an Ordinal Scale, a ranking, from cardinal data is always possible (Arrow 1974).

2. An Ordinal Scale can never produce a series of cardinal numbers (Arrow 1974).

3. An Ordinal Scale of a certain kind, a ranking, can be translated in an ordinal scale of another kind.

In application of axiom 3, we shall translate the ordinal scales of the three methods of MULTIMOORA in other ordinal scales.

\subsection{Ordinal Dominance, being dominated, transitiveness and equability}

Stakeholders or their representatives may give a different importance to objectives in a multi-objective problem but this is not the case with the three methods of MULTIMOORA. These three methods represent all possible methods with dimensionless measures in multi-objective optimization and one can not argue that one method is better than or more important than the others.

\section{Ordinal Dominance}

Absolute Dominance means that an alternative, solution or project is dominating absolutely in ranking all other alternatives, solutions or projects, which are all being absolutely dominated. This absolute dominance shows as rankings for MULTIMOORA: (1-1-1).

General Dominance in two of the three methods with a P b P c Pd (P preferred to) is for instance of the form:

(d-a-a) is generally dominating (c-b-b)

(a-d-a) is generally dominating (b-c-b)

(a-a-d) is generally dominating (b-b-c)

and further on, transitiveness plays fully.

\section{Transitiveness}

If $\mathrm{a}$ dominates $\mathrm{b}$ and $\mathrm{b}$ dominates $\mathrm{c}$ than a will dominate $\mathrm{c}$.

\section{Overall Dominance of one alternative on another}

For instance (a-a-a) is overall dominating (b-b-b) which is overall being dominated by (a-a-a).

\section{Equability}

Absolute Equability has the form: for instance (e-e-e) for 2 alternatives.

Partial Equability of 2 on 3 exists e. g. (5-e-7) and (6-e-3). 


\section{Circular Reasoning}

Despite all distinctions in classification, some contradictions remain possible in a kind of Circular Reasoning.

We can cite the case of:

object A (11-20-14) dominates generally object B (14-16-15)

object B (14-16-15) dominates generally object C (15-19-12)

but object C (15-19-12) dominates generally object A (11-20-14).

In such a case, the three objects receive the same ranking.

Similar rules apply for the three methods of MULTIMOORA with no significance coefficients proposed, as the three methods are assumed to have the same importance.

\section{Previous applications of MOORA and MULTIMOORA}

MOORA and MULTIMOORA made many applications in the micro-economic as well as in the macro-economic field.

In the micro-economic field can be mentioned for instance: privatization (Brauers 2004b; Brauers, Zavadskas 2006), facilities management (Brauers 2004a), redevelopment alternatives for buildings (Brauers et al. 2006), location theory (Brauers, Zavadskas 2008), highway construction in Thüringen, Germany (Brauers et al. 2008b), Contractor's ranking (Brauers et al. 2008a), heating losses in a building (Kracka et al. 2010), bank loans (Brauers, Zavadskas 2011a) and manufacturing (Chakraborty 2011).

In the macro-economic field can be mentioned for instance: Poland and Lithuania facing the European Union (Brauers et al. 2007), the Well-Being Economy (Brauers 2008), the Industrialization of Tanzania (Brauers, Zavadskas 2010b), the development of the regions in Lithuania (Brauers, Ginevicius 2009; Brauers et al. 2010), the economy of the Belgian Regions tested with MULTIMOORA (Brauers, Ginevicius 2010), Lithuania in the European Union (Balezentis et al. 2010), Strategy Europe 2020 (Balezentis et al. 2011) and Project Optimization for China (Brauers, Zavadskas 2011b).

\section{Application on the Belgian shares}

Following table 3 brings the ranking of the shares of the BEL20 Index ${ }^{2}$. The first figure between brackets represents the outcome of the Ratio System, the $2^{\text {nd }}$ of the Reference Point Method and the $3^{\text {rd }}$ of the Full Multiplicative Form. In Table 3, bold figures show a dominating effect.

Suez is Absolute Dominating (three ranks on three) and Omega Pharma is General Dominating (two ranks on three) Delhaize. By Transitiveness as Suez is dominating Omega Pharma it also dominates Delhaize etc.

\footnotetext{
2 The detailed mathematical operations concerning this table are available on demand from the authors.
} 
Table 3. Ranking of Preference for the Shares of the BEL20 Index (banks excluded)

\begin{tabular}{|c|c|}
\hline RANKING & SHARES \\
\hline 1 & Suez $(1-1-1)$ \\
\hline 2 & Omega Pharma (2-6-2) \\
\hline 3 & Delhaize (4-3-4) \\
\hline 4 & Ackermans-VH(3-4-6) \\
\hline 5 & Cofimmo (5-2-9) \\
\hline 6 & NPM (11-5-3) \\
\hline 7 & Belgacom (7-10-7) \\
\hline 8 & Telenet (8-7-8) \\
\hline 9 & Befimmo (6-10-11) \\
\hline 10 & AB-Inbev (9-8-12) \\
\hline 11 & Mobistar (12-15-5) \\
\hline 12 & Colruyt (14-9-14) \\
\hline 13 & UCB (10-10-15) \\
\hline 14 & Solvay (13-10-16) \\
\hline 15 & GBL (15-16-10) \\
\hline 16 & Umicore (16-14-17) \\
\hline 17 & Bekaert (17-17-13) \\
\hline
\end{tabular}

\section{Shortcomings of the application}

\subsection{General remarks}

1. The application concerns the past. Pure extrapolation has no sense for such a fluctuating market. Many other factors have to be taken into consideration. An effort is made here to add some more reflections.

2. Regularly revisions are needed. The objectives concern here the situation of the Belgian Stock Exchange on December 30, 2010, which means that the General Assemblies of 2010 are included with the dividend payments for the book year 2009 or 2009-2010. At least revisions are necessary after later yearly Dividend Payments and after the end of each calendar year.

3. Companies with an effective management are assumed. A thorough study work on each company is necessary, for instance on the behavior of the managers, the real book value of the company. Eventually Strategic Management, Crisis Management, Project Risk Management or Scenario Planning have to be foreseen.

4. Finally, there are the Unknown Unknowns or may we say the Economics of Uncertainty? For instance, a combination of Earthquake, Tsunami and Atomic Plants disasters is certainly fatal for insurance companies. 


\subsection{Some special remarks around the BEL20 Index}

Certainly, the BEL20 Index is not at the level of the London FTSE100, the German DAX30 or the French CAC40.

The Belgian BEL20 Index dates only from after the Second World War. The index was always characterized by changes. Changes in composition are typical for the BEL20 Index, due to severe regulations and the rather small size of the Belgian companies. For instance after December 31, 2010, the date of this investigation, NPM was dissolved. Since 2011 the following other changes took place. The owners took Omega Pharma from the Belgian Stock Exchange and the bad bank Dexia and the telecom operator Mobistar were replaced. The newcomers were D'Ieteren, car dealers, Elia, the owner of the high Voltage lines in Belgium, Thrombogenics, a pharmaceutical firm, and Delta Lloyd, a Dutch bank. In fact, the BEL20 counts two foreign firms: Suez (French) and Delta Lloyd (Dutch).

In addition, since the birth of NYSE-EURONEXT, grouping the places of New York, Brussels, Paris, Amsterdam and Lisbon, the importance of the place of Brussels diminished considerably. Therefore, this investigation is just an exercise how to operate similar studies. Perhaps a study on London, New York, Paris, Frankfurt or Amsterdam would be more useful.

The study concerns an optimal way to study the behavior of shares on a Stock Exchange in the financial centers of the world.

\section{Conclusions}

Is it possible to classify shares of companies on the Stock Exchange thanks to a quantitative method? Therefore, the MULTIMOORA, a method for multi-objective optimization was chosen. The internal mechanical solution of a Ratio System, producing dimensionless numbers, is preferred to weights. In addition, the ratio system creates the opportunity to use a second approach: a non-subjective Reference Point Theory. For that purpose, the Reference Point Theory uses the ratios found in the ratio system as co-ordinates for the alternative solutions, which are then compared to a Maximal Objective Reference Point. The results are still more convincing if a Full Multiplicative Form joined MOORA, three methods assembled under the name of MULTIMOORA. At that moment, the control by three different approaches forms a guaranty for a solution being as non-subjective as possible. As it is not allowed to calculate the sum of the three obtained ranks, a theory of Ordinal Dominance is developed in order to remain in the ordinal sphere.

The Belgian BEL20 Index was used as a test case. Certainly, the BEL20-Index is not at the level of the London FTSE100, the German DAX30 or the French CAC40. Moreover, it lost much of its importance when the Stock Exchange of Brussels was incorporated into NYSE-EURONEXT.

If the MULTIMOORA method is used for share evaluation, the evaluation would have to be reconsidered regularly, perhaps with including more objectives. Until now, eight 
objectives were considered, with the importance of the objectives measured by the opinion of a selection of analysts assumed as a ninth objective. With these changes, MULTIMOORA could become a favorable instrument to follow the evolution of share quotations all over the world. Therefore, the author hopes that similar studies on the most famous share indices of the major countries would be made one day. In order to see similarities and dissimilarities it may be preferable to use the same objectives and the same method for comparing these most famous share indices.

\section{References}

Allen, R. G. D. 1957. Mathematical economics. London: Macmillan.

Arrow, K. J. 1974. General economic equilibrium: purpose, analytic techniques, collective choice, American Economic Review June: 253-272.

Balezentis, A.; Balezentis, T.; Brauers, W. K. 2011. Implementation of the strategy Europe 2020 by the multi-objective evaluation method MULTIMOORA, Economics and Management 2: 6-21.

Balezentis, A.; Balezentis, T.; Valkauskas, R. 2010. Evaluating situation of Lithuania in the European Union: structural indicators and MULTIMOORA method, Technological and Economic Development of Economy 16(4): 578-602. ISSN 2029-4913. http://dx.doi.org/10.3846/tede.2010.36

Brans, J. P.; Mareschal, B.; Vincke, P. 1986. How to select and how to rank projects: the PROMETHEE method, EJOR 24(2): 228-238. http://dx.doi.org/10.1016/0377-2217(86)90044-5

Brans, J. P.; Mareschal, B.; Vincke, P. 1984. Prométhée: a new family of outranking methods in multicriteria analysis, in J. Brans (Ed.). Proceedings of the IFORS 84 Conference. Washington, 408-421.

Brauers, W. K.; Balezentis, A.; Balezentis, T. 2011. MULTIMOORA for the EU member states updated with fussy number theory, Technological and Economic Development of Economy 17(2): 259-290. ISSN 2029-4913. http://dx.doi.org/10.3846/20294913.2011.580566

Brauers, W. K.; Zavadskas, E. K. 2011a. MULTIMOORA optimization used to decide on a bank loan to buy property, Technological and Economic Development of Economy 17(1): 174-188. ISSN 2029-4913. http://dx.doi.org/10.3846/13928619.2011.560632

Brauers, W. K.; Zavadskas, E. K. 2011b. From a centrally planned economy to multi-objective optimization in an enlarged project management. The case of China, Economic Computation and Economic Cybernetics Studies and Research 45(1): 167-188. ISSN 0424-267X.

Brauers, W. K.; Zavadskas, E. K. 2010a. Project management by MULTIMOORA as an instrument for transition economies, Technological and Economic Development of Economy 16(1): 5-24. ISSN 2029-4913. http://dx.doi.org/10.3846/tede.2010.01

Brauers, W. K.; Zavadskas, E. K. 2010b. Robustness in the MULTIMOORA model, the example of Tanzania, Transformations in Business and Economics 9(3): 67-83.

Brauers, W. K.; Zavadskas, E. K. 2010c. Is robustness really robust? Robustness from the point of view of Statistics and Econometrics with an application for Multi-Objective Optimization, Chapter 2, in C. Zopounidis, M. Doumpos, et al. (Eds.). Multiple criteria decision aiding. Hauppage, NY: Nova Science Publishers, Inc., 17-42. ISBN 978-1-61668-231-6.

Brauers, W. K.; Zavadskas, E. K. 2008. Multi-objective optimization in location theory, with a simulation for a department store, Transformations in Business and Economics 7(3): 163-183. ISSN 1648-4460.

Brauers, W. K.; Zavadskas; E. K.; Turskis, Z.; Vilutiene, T. 2008a. Multi-objective contractor's ranking by applying the Moora method, Journal of Business Economics and Management 9(4): 245-256. ISSN 1611-1699. http://dx.doi.org/10.3846/1611-1699.2008.9.245-255 
Brauers, W. K.; Zavadskas, E. K.; Peldschus, F. 2008b. Multi-objective decision-making for road design, Transport 23(3): 183-193. http://dx.doi.org/10.3846/1648-4142.2008.23.183-193

Brauers, W. K.; Ginevicius, R.; Podvesko, V. 2010. Regional development in Lithuania considering multiple objectives by the MOORA method, Technological and Economic Development of Economy 16(4): 613-640. ISSN 2029-4913. http://dx.doi.org/10.3846/tede.2010.38

Brauers, W. K.; Ginevicius, R. 2010. The economy of the Belgian Regions tested with MULTIMOORA, Journal of Business Economics and Management 11(2): 173-209. ISSN 1611-1699. http://dx.doi.org/10.3846/jbem.2010.09

Brauers, W. K.; Ginevicius, R. 2009. Robustness in regional development studies, the case of Lithuania, Journal of Business Economics and Management 10(2): 121-140. ISSN 1611-1699. http://dx.doi.org/10.3846/1611-1699.2009.10.121-140

Brauers, W. K.; Ginevicius, R.; Zavadskas, E. K.; Antucheviciene, J. 2007. The European Union in a transition economy, Transformations in Business and Economics 6(2): 21-37. ISSN 16484460 .

Brauers, W. K.; Zavadskas; E. K. 2006. The Moora method and its application to privatization in a transition economy, Control and Cybernetics 35(2): 443-468.

Brauers, W. K.; Zavadskas, E. K.; Turskis, Z.; Antucheviciene, J. 2006. Evaluating redevelopment alternatives of buildings with an application of the MOORA method, in Simulation and Optimisation in Business and Industry. Kaunas: Technologija, 131-135. ISBN 9955-25-061-5.

Brauers, W. K. 2008. Multi-objective decision making by reference point theory for a wellbeing economy, International Journal of Operations Research 8(1): 89-104.

http://dx.doi.org/10.1007/s12351-008-0013-7

Brauers, W. K. 2004a. Multi-objective optimization for facilities management, Journal of Business Economics and Management 5(4): 173-182. ISSN 1611-1699.

Brauers, W. K. 2004b. Multiobjective optimization (MOO) in privatization, Journal of Business Economics and Management 5(2): 59-66. ISSN 1611-1699.

Brauers, W. K. 2004c. Optimization methods for a stakeholder society, a revolution in economic thinking by multi-objective optimization, Series: Nonconvex Optimization and its Applications, Volume 73. Boston, Dordrecht, London: Kluwer Academic Publishers and Springer. 342 p. ISBN 1-4020-7681-9.

Chakraborty, S. 2011. Applications of the MOORA method for decision making in manufacturing environment, International Journal Advanced Manufacturing Technology 54(9-12): 1155-1166. http://dx.doi.org/10.1007/s00170-010-2972-0

De Jong, F. J. 1967. Dimensional analysis for economists. Amsterdam: North-Holland. 28 p.

Hwang, Ching-Lai; Kwansun Yoon. 1981. Multiple attribute decision making, methods and applications. Lecture notes in economics and mathematical systems. Berlin: Springer. 186 p.

http://dx.doi.org/10.1007/978-3-642-48318-9

Karlin, S.; Studden, W. J. 1966. Tchebycheff systems: with applications in analysis and statistics. New York. Interscience: Publishers.

Keeney, R. L.; Raiffa, H. 1993. Decisions with multiple objectives. Preferences and value tradeoffs. USA: Cambridge University Press.

Keeney, R. L. 1973. A decision analysis with multiple objectives: the Mexico City airport, The Bell Journal of Economics and Management Sciences 4(1): 101-117.

Kracka, M.; Brauers, W. K.; Zavadskas, E. K. 2010. Ranking heating losses in a building by applying MULTIMOORA, Inzinerine Ekonomika - Engineering Economics 21(4): 352-359.

MacCrimmon, K. R. 1968. Decision making among multiple attribute alternatives. A survey and consolidated approach. Santa Monica (CAL): The Rand Corporation. 
Miller, D. W.; Starr, M. K. 1969. Executive decisions and operations research, 2nd edition. Englewood Cliffs, N.J.: Prentice-Hall Inc.

Opricovic, S.; Tzeng, G-H. 2004. Compromise solution by MCDM methods: a comparative analysis of VIKOR and TOPSIS, EJOR 156: 445-455.

http://dx.doi.org/10.1016/S0377-2217(03)00020-1

Roy, B.; Benayoun, R.; Sussman, B. 1966. ELECTRE. Société d'Economie et de Mathématique appliquées, Paris.

Saaty, T. L. 1988. The analytic hierarchy process. New York: Mcgraw-Hill.

Teekens, R.; Koerts, J. 1972. Some statistical implications of the log transformation of multiplicative models, Econometrica 40(5): 793-819. http://dx.doi.org/10.2307/1912069

White, L. J. 2010. The credit rating agencies, Journal of Economic Perspectives 24(2): 211-226. http://dx.doi.org/10.1257/jep.24.2.211

Willem K. M. BRAUERS. Doctor honoris causa Vilnius Gediminas Technical University, was graduated as: Ph.D. in economics (Un. of Leuven), Master of Arts (in economics) of Columbia Un. (New York), Master in Economics, Master in Management and Financial Sciences, Master in Political and Diplomatic Sciences and Bachelor in Philosophy (all of the Un. of Leuven). He is professor ordinarius at the Faculty of Applied Economics of the University of Antwerp, Honorary Professor at the University of Leuven, the Belgian War College, the School of Military Administrators and the Antwerp Business School. He was a research fellow in several American institutions like Rand Corporation, the Institute for the Future, the Futures Group and extraordinary advisor to the Center for Economic Studies of the University of Leuven. He was consultant in the public sector, such as the Belgian Department of National Defense, the Department of Industry in Thailand, the project for the construction of a new port in Algeria (the port of Arzew) and in the private sector such as the international seaport of Antwerp and in electrical works. He was Chairman of the Board of Directors of SORCA Ltd.Brussels, Management Consultants for Developing Countries, linked to the worldwide group of ARCADIS. At the moment he is General Manager of CONSULTING, Systems Engineering Consultants. Brauers is member of many international scientific organizations. His specialization covers: Optimizing Techniques with Different Objectives, Forecasting Techniques, Input-Output Techniques and Public Sector Economics such as for National Defense and for Regional Sub-optimization. His scientific publications consist of seventeen books and several hundreds of articles and reports in English, Dutch and French.

Romualdas GINEVIČIUS. Professor, Dr Habil, Head of the Department of Enterprise Economics and Management, construction engineer and economist. The author of more than 350 research papers and over 20 scientific books; Editor-in-Chief of the "Journal of Business Economics and Management" (located in ISI database "Web of Science") and the journal "Business: Theory and Practice". Research interests: organization theory, complex quantitative evaluation of social processes and phenomena. 